\title{
ASGAR (Animasi Software Geogebra dan Alat Peraga) untuk Mendukung Proses Pembelajaran Matematika di Kelas
}

\author{
Usman Aripin $^{1 *}$, Wahyu Setiawan¹, Heris Hendriana ${ }^{1}$, Ani Ainun Masruroh ${ }^{1}$ \\ ${ }^{1}$ Institut Keguruan dan Ilmu Pendidikan Siliwangi, Jl. Terusan Jend. Sudirman, Baros, Kec. Cimahi Tengah, \\ Kota Cimahi, Jawa Barat 40521 \\ *Email Korespondensi: usman.aripin@ikipsiliwangi.ac.id
}

\begin{abstract}
Abstrak
Perkembangan teknologi mempengaruhi semua aspek kehidupan, begitupun di dunia pendidikan. Tuntutan guru menjadi lebih banyak, selain administrasi yang harus diselesaikan, ditambah dengan keharusan untuk mampu menggunakan teknologi. Salah satu alternatif solusinya adalah dengan menerapkan pelatihan ASGAR yang bertujuan untuk mendukung kegiatan guru-guru dalam pembelajaran matematika. Metode yang digunakan yaitu berupa workshop dan pelatihan secara langsung menggunakan ASGAR kepada guru mulai dari tingkatan SD, SMP dan SMA yang ada di pangalengan. Hasil pelatihannya yaitu pelatihan ASGAR ini mndapat respon positif dari para guru peserta pelatihan.mengetahui bahwa pembelajaran matematika bisa dilakukan dengan menarik sehingga pembelajaran tidak akan terasa membosankan, dan menggunakan media tersebut dalam penyampaian konsep dari suatu materi dengan efisien dan efektif, mengeksplorasi media tersebut sesuai dengan materi yang ingin disampaikan oleh guru.
\end{abstract}

Kata kunci: ASGAR; TIK; media pembelajaran.

\begin{abstract}
Technological developments affect all aspects of life, as well as in the world of education. Teacher demands become more numerous, in addition to administration that must be completed, coupled with the necessity to be able to use technology. One alternative solution is to implement ASGAR training which aims to support the activities of teachers in learning mathematics. The method used is in the form of workshops and direct training using ASGAR to teachers ranging from elementary, junior high and high school levels in Pangalengan. The results of the training namely ASGAR training received a positive response from the trainees of the trainees. Knowing that mathematics learning can be done attractively so that learning will not feel boring, and use the media in delivering concepts from a material efficiently and effectively, exploring the media in accordance with material to be conveyed by the teacher.
\end{abstract}

Keywords: ASGAR; ICT; learning Media.

Format Sitasi: Aripin, U., Setiawan, W., Hendriana, H., \& Masruroh, A. A. (2019). Pelatihan ASGAR (Animasi Software Geogebra Dan Alat Peraga) untuk Mendukung Kegiatan Belajar Mengajar kepada GuruGuru di Kecamatan Pangalengan. Jurnal Solma. Vol. 09(2), 354-360. Doi: http://dx.doi.org/10.22236/solma.v9i2.3975

Diterima: 2 Desember 2019 | Revisi: 20 Agustus 2020 | Dipublikasikan 30 Oktober 2020

(C) 2020 Oleh authors. Lisensi Jurnal Solma, LPPM-Uhamka, Jakarta. Artikel ini bersifat open access yang didistribusikan di bawah syarat dan ketentuan Creative Commons Attribution (CC BY) license. (http://creativecommons.org/licenses/by/4.0/).

\section{PENDAHULUAN}

Perkembangan ilmu pengetahuan memunculkan Era baru yang dinamakan era digital. Era ini adalah era dimana semua kegiatan sudah menggunakan teknologi informasi dan komunikasi atau yang secara internasional dikenal dengan istilah Information Communication and Technologies (ICT) mulai dari transaksi sampai dengan penggunaan transportasi. Generasi pada era ini biasa disebut juga dengan generasi milenial. Generasi 
milenial adalah generasi yang mana dalam keseharian tak pernah lepas dari teknologi. Mulai dari lingkup bersosialisasi, belanja sampai dengan belajar tak lepas dari teknologi. Pesatnya perkembangan teknologi saat ini menyebabkan tak ada satupun orang yang tidak pernah bersentuhan langsung dengan teknologi. Untuk itu teknologi di generasi ini sangatlah penting dan menjadi salah satu kebutuhan primer setiap orang. Dunia pendidikan saat ini pun dituntut untuk mampu mengimbangi pembelajaran dengan teknologi dalam setiap kegiatannya (Rahim, 2016). Penerapan TIK/ ICT memiliki keunggulan tersedianya informasi secara luas, cepat, dan tepat, adanya kemudahan dalam proses pembelajaran, administrasi akademik, dan administrasi keuangan serta dukungan teknologi untuk memudahkan mengakse informasi tersebut di atas. Penerapan TIK/ ICT juga memiliki keunggulan khas yaitu tidak terbatasi oleh tempat dan waktu. Dari pernyataan tersebut jelas bahwa proses pembelajaran berinteraksi langsung dengan teknologi. Untuk itu diperlukan media pembelajaran inovatif untuk mendukung hal tersebut.

Pengetahuan pendidik akan mempengaruhi kemmpuan peserta didik dalam dalam pencapaian matematika sehingga dalam mengoptimalkan kegiatan belajar mengajar perlu adanya strategi yang inovatif berbasis teknologi untuk meningkatkan kualitas pembelajaran (Hidayat \& Aripin, 2019; Mulyawati \& Kowiyah, 2018; Setiawan \& Andika Sari, 2018) Disampaikan oleh (Muhson, 2010) bahwa pembelajaran inovatif yang melibatkan teknologi informasi menjadi hal wajib dalam kegiatan belajar mengajar. Kalimat tersebut jelas megatakan bahwa guru di era ini dituntut untuk menguasai teknologi, hal tersebut dilakukan supaya dapat mengefisien dan mengefektifkan waktu guru dalam penyampaian konsep dari suatu materi serta mengajak siswa bahwa teknologi saat ini tidak cenderung berhubungan dengan media sosial semata, namun dalam bidang pendidikan pun dapat memberikan manfaat yang besar.

Berdasarkan hasil penelitian (Budiman, 2017) peran teknologi informasi dalam pembelajaran, selain membantu siswa dalam belajar juga memiliki peran yang cukup berpengaruh bagi guru terutama dalam pemanfaatan fasilitas untuk kepentingan memperkaya kemampuan mengajarnya. Namun pada kenyataanya kebanyakan guru matematika khususnya didaerah masih kurang menguasai media pembelajaran berbasis komputer. PT Microsoft Indonesia menyatakan prihatin bila para guru masih menggunakan metode mengajar tradisional yang cenderung monoton dan membosankan bagi siswa (Noni, 2013).

Berdasarkan peraturan pemerintah No.74 tahun 2008 (Darmawan et al., 2019) seorang guru minimalnya harus menguasai teknologi dan informasi. Selain itu guru dituntut untuk bisa mengembangkan kemampuan memanfaatkan teknologi dalam membuat media pembelajaran representatif sebagai media penunjang dalam proses pembelajaran (Amirullah \& Susilo, 2018). Oleh karena itu pendidikan harus berupaya membuat inovasi pembelajaran berbasis teknologi agar mampu mengalihakn perhatian siswa untuk memanfaatkan teknologi sebagai sarana pembelajaran, dan mempermudah guru untuk membuat sebuah media pembelajaran yang menarik perhatian siswa, mengefektifkan dan mengefisiensikan proses pembelajaran. Perkembangan teknologi selalu diikuti oleh pemikiran inovatif, bentuk dari pemikiran inovatif yaitu adanya media pembelajaran yang sesuai dengan generasi saat ini. Media tersebut yaitu ASGAR (Animasi software Geogebra dan Alat Peraga). ASGAR 
adalah salah satu media yang dapat digunakan dan menjadi inovasi baru dalam kegiatan belajar mengajar di kelas.

Inovasi ini dapat digunakan kapanpun dan dimanapun kita membutuhkannya. Untuk itu media ini sangatlah bermanfaat dalam proses pembelajaran. Agar inovasi ini dapat digunakan oleh para Guru, maka diadakanlah pelatihan. Pelatihan ini mengajak guru untuk dapat mengimbangi perkembangan saat ini. ASGAR di ajarkan supaya guru dapat menyampaikan materi sesuai dengan konsep namun tidak memerlukan tenaga lebih untuk membuatnya, yang diperlukan hanyalah laptop dan proyektor dalam penyampaian materi tersebut nantinya. ASGAR tidak terpatok pada satu materi, guru dapat bereksplorasi sesuai dengan materi dan konsep yang ingin disampaikan.

\section{MASALAH}

Perkembangan teknologi mempengaruhi semua aspek kehidupan, begitupun di dunia pendidikan. Tuntutan guru menjadi lebih banyak, selain administrasi yang harus diselesaikan, sekarang ditambah dengan keharusan untuk mampu menggunakan teknologi.

Guru saat ini tidak semuanya berusia muda, masih banyak guru yang sudah berumur. Namun guru berusia muda pun tak menjamin mampu menguasai teknologi dan menerapkannya dalam pembelajaran. Selain dari itu, mencari tahu teknologi yang akan sesuai dengan materi yang disampaikankan memerlukan waktu yang tidak sebentar.

Media konvensional yang biasa digunakan untuk menyampaikan konsep dari suatu materipun menjadi salah satu permasalahan. Seperti kita ketahui, pemnuatan media pembelajaran konvensional membutuhkan waktu dan tenaga yang ekstra, tidak hanya dalam persiapannya saja, dalam pelaksanaan pembelajarannya pun membutuhkan waktu yang cukup lama.

\section{METODE PELAKSANAAN}

Metode yang digunakan yaitu berupa workshop dan pelatihan secara langsung menggunakan ASGAR kepada guru mulai dari tingkatan SD, SMP dan SMA yang ada di pangalengan.

1. Workshop

Pada kegiatannya, guru menyimak terlebih dahulu apa itu ASGAR dan apa manfaatnya dalam proses pembelajaran di kelas. Serta dijelaskan tentang langkah-langkah cara membuat ASGAR.

2. Pelatihan

Setelah penyampaian mengenai ASGAR, guru diajak langsung untuk mempraktekan cara membuat ASGAR sendiri dengan di pandu oleh pemateri serta buku panduan yang sudah disiapkan oleh pemateri sebelumnya.

Melalui pelatihan ini diharapkan guru dapat mencoba pembelajaran menggunakan media ASGAR di kelasnya masing-masing. Media ASGAR ini selain membantu guru dalam penyampaian konsep, hal tersebut juga akan menarik perhatian siswa terhadap pembelajaran konsep tersebut, sehingga siswa dapat memahami dengan sendirinya maksud dari konsep yang ingin disampaikan oleh guru. 


\section{PEMBAHASAN}

Kegiatan workshop dan pelatihan ini melibatkan dua orang dosen matematika dan satu mahasiswa IKIP Siliwangi. Workshop dan pelatihan tersebut bermitra dengan SMAN 1 Pangalengan dan diikuti oleh seluruh Guru SD, SMP dan SMA yang ada di Pangalengan. Tim pengabdian dipilih berdasarkan bidang keahlian sehingga dapat menunjang pengabdian kepada masyarakat ASGAR adalah media pembelajaran berbasis ICT yang dapat digunakan dimana saja dan kapan saja. Adanya media pembelajaran berbasis teknologi informasi dapat meningkatkan minat baru dalam belajar, sebagaimana hasil penelitian yang dilakukan (Adam, 2015) untuk itu kegiatan pelatihan ASGAR diharapkan dapat membantu guru dalam kegiatan belajar mengajar.

Pelatihan ASGAR yang dilaksanakan di SMAN 1 Pangalengan dengan mengundang guru SD, SMP dan SMA yang ada di pengalengan berjalan dengan lancar. Antusias guru terhadap media pembelajaran ASGAR sangatlah baik, hal tersebut terlihat dari setiap langkah pembuatan yang diikuti dengan seksama mulai dari awal pembuatan sampai dengan akhir. Pada pelatihan tersebut, tidak hanya guru dari kalangan muda saja yang mengikuti pelatihan dengan semangat, namun guru dari kalangan yang sudah berumur-pun memiliki semangat yang tinggi. Hal tersebut terlihat ketika guru tersebut bertanya ulang perihal langkah yang sebelumnya telah beliau lalui, sampai beliau bisa dan mampu menyelesaikan langkah-langkah dari pembuatan ASGAR tersebut.

Melihat antusias tersebut diharapkan dari pelatihan media ASGAR guru dapat bereksplorasi dengan materi dan konsep-konsep lainnya untuk penyampaiannya di kelas, dan diharapkan konsep yang disampaikan akan diterima dengan baik oleh siswa sehingga tidak ada kesalahan dalam penerimaan konsep.

Kegiatan workshop dan pelatihan ini melibatkan dua orang dosen matematika dan satu mahasiswa IKIP Siliwangi. Workshop dan pelatihan tersebut bermitra dengan SMAN 1 Pangalengan dan diikuti oleh seluruh Guru SD, SMP dan SMA yang ada di Pangalengan. Tim pengabdian dipilih berdasarkan bidang keahlian sehingga dapat menunjang pengabdian kepada masyarakat.

Berikut adalah dokumentasi dari workshop dan pelatihan ASGAR kepada guru SD, SMP dan SMA di Pangalengan:

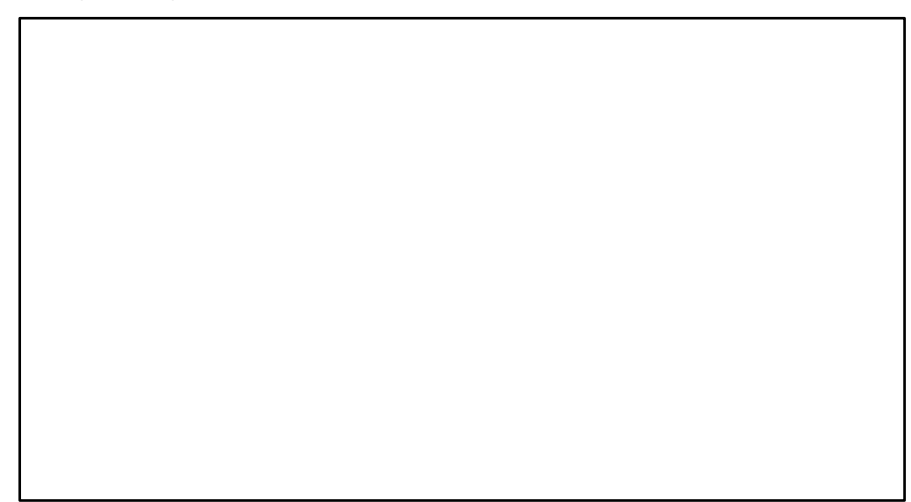

Gambar 1. Kegiatan Workshop media pembelajaran ASGAR

Pada tahap pertama dijelaskan terlebih dahulu tentang toolbar yang ada pada software geogebra dan penjelasan tentang bagaiamana cara penggunaannya. Penjelasan ini sangat 
penting karena sebagian besar guru belum mengetahui tentang aplikasi ini. Selain itu pembelajaran dikelas masih menggunakan metode konvensional. Oleh karenanya pembelajaran dengan softwrae geogebra sangatlah penting karena dapat mengkonstruksi materi dengan mudah dan praktis tanpa harus mengeluarkan biaya. Hal ini ditegaskan oleh Rizki \& Wildaniati (Purwasih et al., 2018) adanya pengaruh yang sangat signifikan pmebelajaran menggunakan ICT terhadap kemampuan matematis siswa.
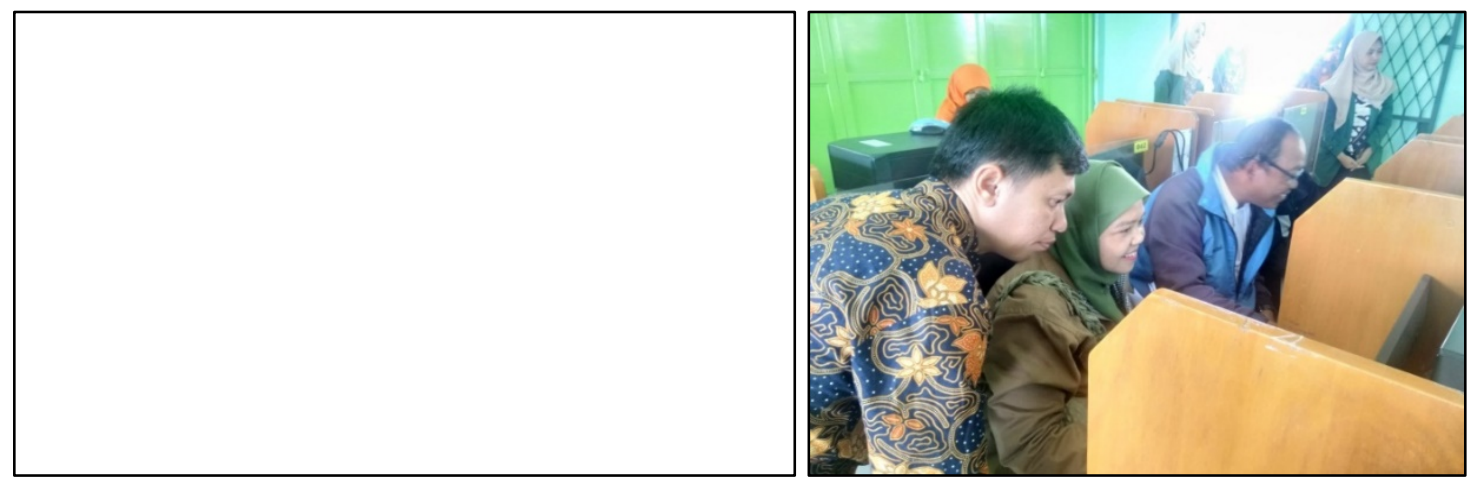

Gambar 2. Pelatihan ASGAR kepada Guru SD, SMP dan SMA

Tahap ini guru-guru mencoba secara langsung penggunaan software geogebra untuk membuat media atau alat peraga matematik yang dibuat dalam bentuk software. Guru-guru memberikan respon positif terhadap materi dan aplikasi software ini karena mengetahui manfaatnya dalam pembelajaran matematika. Pada saat melakukan praktik masih terdapat guru-guru yang masih kaku dalam menggunakan software geogebra hal ini karena sebagian peserta pelatihan belum terbiasa menggunakan ICT. Selain itu meskipun sudah memahami materi pelatihan ini masih memungkinkan lupa karena banyak langkah-langkah yang harus ditempuh jika membuat sebuah media. Oleh karena itu peserta pelatihan diberikan modul tutorial pembuatan media software geogebra agar dapat mengingat dan mengembangkan materi tersebut dalam kegiatan belajar mengajar.

Dalam mengoptimalkan kualitas pembelajaran menurut Anwar (Handayani \& Amirullah, 2019) sangat penting untuk meningkatkan kompetensi guru. Software gepgebra ini sangat membantu dalam pembelajaran matematika selain sebagai media pembelajaran juga sebagai sarana untuk mengecek perhitungan yang salah, membantu membuat soal terutama soal yang terdapat bangun-bangun geometri. Hal ini sejalan dengan pendapat (Qurrohman et al., 2018) penerapan komputasi matematika geogebra pada mata pelajaran matematika, diharapkan kedepan dapat pula diterapkan pada matapelajaran lain yang ada unsur matematika. (Somantri et al., 2019) pelatihan teknologi informasi pada guru akan memberikan pemahaman baru untuk menciptakan desain pembelajaran yang lebih inovatif dalam pembelajaran.

Dengan menerapkan pembelajaran dengan media ASGAR ini diharapakan akan mengubah sedikit demi sedikit paradigma matematika yang dianggap sulit menjadi mudah, mengingat matematika salah satu pelajaran yg penting karena hampir disetiap jenjang pendidikan dan seluruh aktivitas manusia tidak akan lepas dari pengetahuan matematis (Aripin, 2015; Aripin \& Purwasih, 2017; Novtiar \& Aripin, 2017). Selain itu media ASGAR menjadi solusi dalam mengatasi permasalahan pembelajaran matematika karena media ini 
dapat mendesain pembelajaran dengan animasi lebih menarik, membangun konsep dengan baik, mengeksplorasi media tersebut sesuai dengan materi yang ingin disampaikan oleh guru dan yang lebih penting dapat mengefektifkan dan mengefisiensikan pembelajaran dikelas.

\section{KESIMPULAN}

Berdasarkan dari kegiatan yang dilaksanakan dapat disimpulkan bahwa dengan adanya pelatihan ASGAR tersebut guru dapat mengetahui bahwa pembelajaran matematika bisa dilakukan dengan menarik sehingga pembelajaran tidak akan terasa membosankan, mengeksplorasi media tersebut sesuai dengan materi yang ingin disampaikan oleh guru dan dapat mengefektifkan dan mengefisiensikan pembelajaran dikelas.

\section{UCAPAN TERIMA KASIH}

Pelaksanaan workshop dan pelatihan ASGAR ini tidak akan terlaksana tanpa adanya bantuan dari berbagai pihak. Untuk itu saya ucapkan terimakasih banyak kepada:

1. IKIP Siliwangi selaku kampus yang menaungi seluruh dosen dan mahasiswa.

2. Fakultas Pendidikan Matematika dan Sains yang telah membantu keberlangsungan kegiatan.

3. Program Studi Pendidikan Matematika yang telah memfasilitasi kegiatan pengabdian

4. SMAN 1 Pangalengan yang telah brekenan memperikan tempat pelaksanaan pengabdian

5. Guru SD, SMP dan SMA se-Pangalengan yang telah turut serta dalam pengabdian.

\section{DAFTAR PUSTAKA}

Adam, S. (2015). Pemanfaatan Media Pembelajaran Berbasis Teknologi Informasi Bagi Siswa Kelas X SMA ANANDA BATAM. Computer Based Information System Journal, 3(2), 78-90.

Amirullah, G., \& Susilo, S. (2018). Pengembangan Media Pembelajaran Interaktif Pada Konsep Monera Berbasis Smartphone Android. WACANA AKADEMIKA: Majalah Ilmiah Kependidikan, 2(1), 38. https://doi.org/10.30738/wa.v2i1.2555

Aripin, U. (2015). P2M STKIP Siliwangi P2M STKIP Siliwangi. Jurnal Ilmiah UPT P2M STKIP Siliwangi, 2(1), 128-136. https://doi.org/10.1523/JNEUROSCI.2378-09.2009

Aripin, U., \& Purwasih, R. (2017). Penerapan Pembelajaran Berbasis Alternative Solutions Worksheet Untuk Meningkatkan Kemampuan Berpikir Kreatif Matematik. AKSIOMA: Jurnal Program Studi Pendidikan Matematika, 6(2), 225-233.

Budiman, H. (2017). Pengertian MYSQL. Pengertian MYSQL:Journal, 8(I), 183.

Darmawan, Nasa, R., \& Yani, A. (2019). Pendampingan Guru-Guru MIS Muhammadiyah Darussalam Dalam Meningkatkan Kualitas Pembelajaran Berbasis Multimedia. Jurnal Solma, 8(2), 171-180.

Handayani, S. L., \& Amirullah, G. (2019). Meningkatkan Pemahaman Guru Sekolah Dasar Melalui Pelatihan Penyusunan Rencana Pelaksanaan Pembelajaran Berbasis Literasi, 4C, PPK dan Hots. Jurnal SOLMA, 8(1), 14. https://doi.org/10.29405/solma.v8i1.2949

Hidayat, W., \& Aripin, U. (2019). The improvement of students ' mathematical understanding ability influenced from argument- driven inquiry learning The 
improvement of students ' mathematical understanding ability influenced from argument-driven inquiry learning. Journal of Physics: Conference Series, 1157(3), 032085. https://doi.org/10.1088/1742-6596/1157/3/032085

Muhson, A. (2010). Pengembangan Media Pembelajaran Berbasis Teknologi Informasi. Jurnal Pendidikan Akuntansi Indonesia, 8(2). https://doi.org/10.21831/jpai.v8i2.949

Mulyawati, I., \& Kowiyah, K. (2018). Pembelajaran Matematika dan IPA Guru SD Melalui $\begin{array}{lllll}\text { Media Pembelajaran Visual. Jurnal SOLMA, } & 7(2), \quad 2 .\end{array}$ https://doi.org/10.29405/solma.v7i2.1652

Noni. (2013). Guru tak Boleh Gaptek.

Novtiar, C., \& Aripin, U. (2017). Meningkatkan Kemampuan Berpikir Kritis Matematis Dan Kepercayaan Diri Siswa Smp Melalui Pendekatan Open Ended. Prisma, 6(2), 119-131. https://doi.org/10.35194/jp.v6i2.122

Purwasih, R., Aripin, U., \& Fitrianna, A. Y. (2018). Implementasi Pembelajaran Worksheet Berbasis ICT Untuk Peningkatan Kemampuan High Order Mathematical Thinking (HOMT) Siswa SMP. JIPM (Jurnal Ilmiah Pendidikan Matematika), 7(1), 57. https://doi.org/10.25273/jipm.v7i1.3841

Qurrohman, M. T., Romadhon, S. A., \& Wulandari, R. (2018). Peningkatan Kompetensi Siswa Dan Guru Smk Dinamika Kota Tegaltentang Pemanfaatan Program Komputasi Matematika Geogebra. Jurnal Pengabdian Kepada Masyarakat, 3, 1-4.

Rahim, M. Y. (2016). Pemanfaatan ICT Sebagai Media Pembelajaran dan Informasi Pada UIN Alauddin Makassar. Sulesana: Jurnal Wawasan Keislaman, 6(2), 127-135. https://doi.org/10.24252/.V6I2.1408

Setiawan, W., \& Andika Sari, V. T. (2018). Pengembangan Bahan Ajar Konsep Diferensial Berbasis Konflik Kognitif. Jurnal Elemen, 4(2), 204. https://doi.org/10.29408/jel.v4i2.511

Somantri, O., Abidin, T., Wijayanto, S., Wibowo, D. S., \& Dairoh. (2019). Peningkatan Kompetensi Guru Melalui PelatihanKeterampilan PembuatanE-Presentation. Jurnal Solma, 8(2), 219-228. 